\title{
A Review of Advances in Artificial Insemination (AI) and Embryo Transfer (ET) in Sheep, with the Special Reference to Hormonal Induction of Cervical Dilation and its Implications for Controlled Animal Reproduction and Surgical Techniques
}

\author{
Ivanka B.R. Candappa and Pawel M. Bartlewski* \\ University of Guelph, Ontario Veterinary College, Department of Biomedical Sciences, 50 Stone Road, Guelph, ON \\ N1G 2W1, Canada
}

\begin{abstract}
Artificial insemination (AI) and embryo transfer (ET) play an important role in the genetic improvement of sheep herds. This review primarily describes the methods that have recently been researched and/or adapted to circumvent the problematic anatomy of the ovine cervix, which prevents the widespread application of transcervical AI and ET in this species. A mechanism of cervical ripening at parturition and the endocrine influences on cervical tone are described as a backdrop to understanding the action of various pharmacological agents used to induce cervical dilation. Although several catheters have been designed to penetrate the ovine cervix, and a specific protocol has been developed for TCAI in sheep (Guelph Method), penetration rates and resulting pregnancy/lambing rates are still inconsistent and unpredictable. Hormonal dilation of the cervix may significantly improve the ease with which the ovine cervix can be traversed. Treatment with $\mathrm{Cervidil}^{\mathbb{Q}}$, a dinoprostone-containing vaginal insert with a slow release mechanism, currently used to induce labor in women, could significantly improve cervical penetration in ewes without adverse effects on uterine contractility. This mode of drug delivery holds promise to result in the development of a safe method to induce cervical dilation for a broad range of transcervical reproductive manipulations in mammalian species including, but not limited to, AI, ET, embryo and oocyte recovery, treatment of ringwomb and transcervical surgical procedures. However, more studies are needed to evaluate the effects of hormonal methods on cervical morphology/pathomorphology, sperm/embryo transport and viability, and fertility in both cyclic and seasonally anovular ewes.
\end{abstract}

Keywords: Transcervical artificial insemination, transcervical embryo transfer, transcervical surgical procedures, sheep, uterine cervix, cervical ripening.

\section{GENERAL INTRODUCTION: BENEFITS OF ASSISTED REPRODUCTIVE TECHNOLOGIES (ARTS) TO LIVESTOCK IMPROVEMENT}

Strategic manipulation and enhancement of herd genetics by employing various reproductive technologies provide a powerful tool for the modern livestock industry to respond to continually increasing demands for improved productivity and quality [1]. Therefore, a vast majority of livestock breeding programs are structured primarily to optimize genetic progress, which directly translates into long-term economic profitability. The rate of genetic improvement within a synthetic population is governed by four key factors; the intensity of selection, defined as the proportion of animals chosen for a particular breeding program; the accuracy of selection, referring to the correctness with which genetically superior animals are selected as replacements for the current herd; the genetic standard deviation, or genetic variation within a herd, and the generation interval, or the amount of time required to replace one generation with the next [2]. The rate of genetic gain can be quantified with the following formula:

*Address correspondence to this author at the University of Guelph, Ontario Veterinary College, Department of Biomedical Sciences, 50 Stone Road, Guelph, ON N1G 2W1, Canada; Tel: 519-824-4120, Ext. 53330; Fax: 519767-1450; E-mail: pmbart@uoguelph.ca
$\Delta G=$ (selection intensity $\cdot$ selection accuracy $\cdot$ genetic standard deviation)/generation interval

Several methods exist to increase the accuracy of selection by providing a means of evaluating animals' genetic merit. Estimated breeding values (EBVs) can be established, which are the measures of genetic strength based not only on the performance of the individual but also on the performance of its close relatives (parents, siblings and progeny) [3]. Advanced statistical methods such as the best-linear-unbiased prediction (BLUP) and molecular methods including marker-assisted selection (MAS) to track the inheritance of particular genes, allow for earlier selection of desirable genetic traits [4]. Although it is possible to select genetically superior individuals with a high degree of accuracy, the genetic gains in livestock production systems achieved through conventional breeding programs are still hampered by limited male and female lifetime reproductive rates, and long generation intervals $[1,5]$. The implementation of assisted reproductive technologies (ARTs) can significantly accelerate genetic progress due to their direct influence on all four factors included in the genetic gain formula. The combined use of ARTs and BLUP/MAS can also lead to the development of optimal breeding programs that maximize genetic improvement over time while maintaining long-term sustainability. The advantages of ARTs collectively lie in the ability to enhance both the male and female pathways of 
gene transmission; the reproductive efficiency of males can be increased through artificial insemination (AI) and of females with multiple ovulation and embryo transfer (MOET) programs. Hence, the genetic advancement of livestock species is largely dependent on the efficiency of these two crucial technologies. In recent years, continued improvements in these methods have been met with a growing demand for the application of AI and MOET in commercial settings, as the numerous benefits they offer are being increasingly recognized.

\section{THE CURRENT STATE AND IMPORTANCE OF AI AND ET IN SHEEP}

The widespread use of AI and MOET has contributed to and continues to procure genetic gains, among several other benefits, in cattle, swine, goats and poultry $[6,7]$; however, the sheep industry has progressed rather slowly in terms of breed improvement in comparison to the aforementioned species [2]. Although sheep have been used extensively in many of the pioneering studies that have led to the development of modern ARTs [6, 8, 9], instigating the commercial use of these technologies in ewes has been impeded by difficulties in performing AI/ET. Currently, the availability of pedigree and performance data, sire reference schemes and cost-effective, efficient methods of superior gene dispersal in sheep is greatly limited [10]. However, the most significant obstacle is the unique anatomical structure of the ewe's reproductive tract, which precludes simple, transcervical passage of an insemination/transfer apparatus.

For AI in sheep, intrauterine semen deposition is a necessity for obtaining high lambing rates. Conception rates after vaginal or mid-cervical AI, although unreliable, are acceptable, albeit only with freshly collected semen that has been subjected to minimal handling. Lambing rates from this method range from $20-40 \%$ with a $400 \times 10^{6}$ spermatozoa per inseminate dose [11], and this rate has been shown to increase with increasing depth of semen deposition (i.e., between the vaginal and intra-cervical AI; $[12,13])$. This low fertility is due mainly to increased propensity for retrograde semen loss from the reproductive tract of the ewe seen with more caudal or "superficial" semen depositions. The consequence of this semen loss is amplified by the fact that various procedures within standard AI protocols may negatively affect sperm transport and viability in the female reproductive tract. Hawk et al., [14] have demonstrated that progestin-releasing intrauterine devices and/or prostaglandin injections employed in the hormonal synchronization for fixed-time AI is ewes are associated with increased sperm death in the anterior cervix and lower portion of the uterus. Secondly, various methods of semen handling and preparation for transport or storage may also contribute to decreased fertility [5]. Frozen-thawed ram semen possesses significantly reduced motility as compared with fresh semen as the

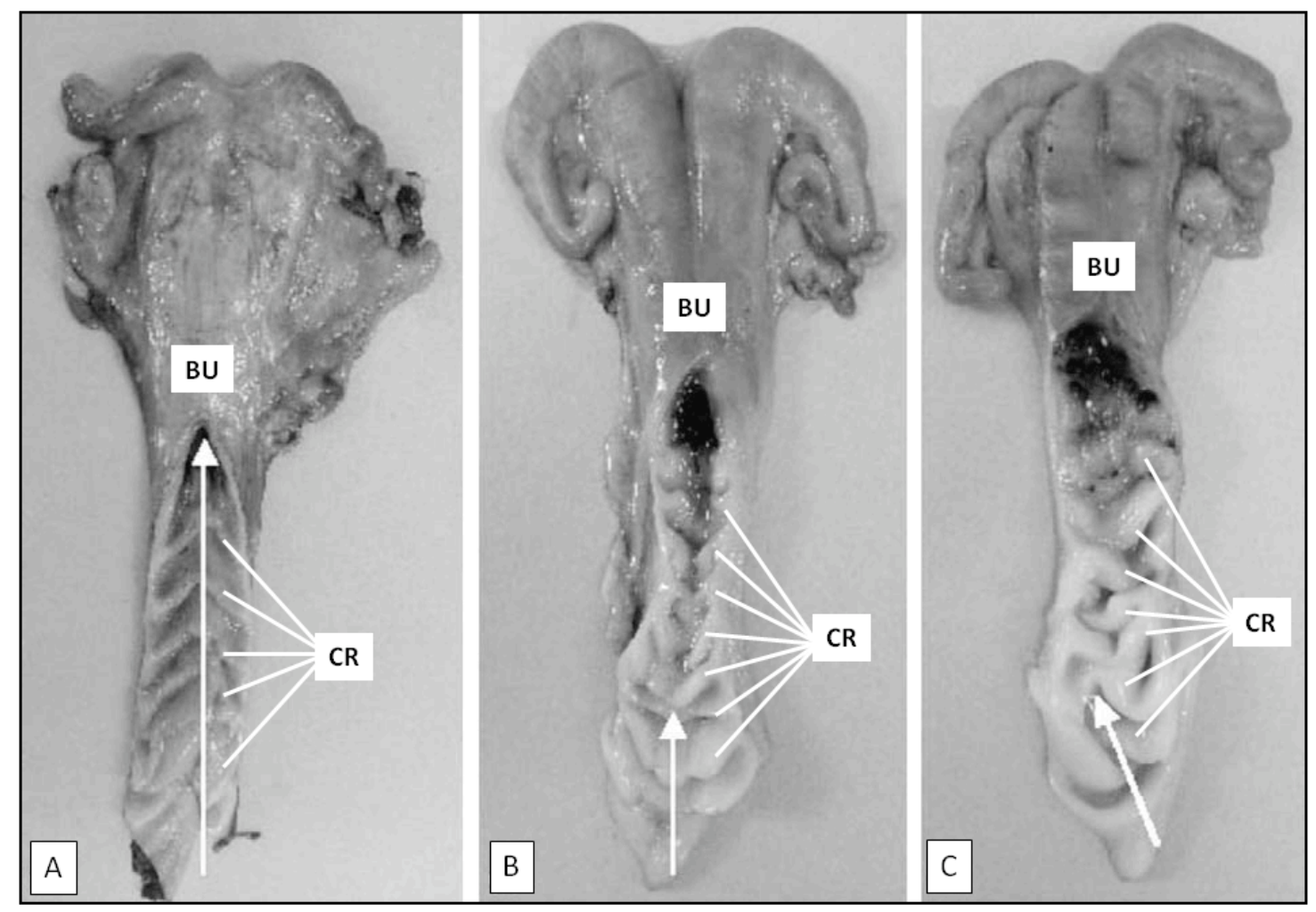

Fig. (1). Cross-sections of the ovine cervix exposing the cervical rings (CR). BU-body of the uterus. The three segments (A-C) depict the morphological classification of cervical grade in ewe: (A)-grade 1 (cervices had a series of complete aligned cervical rings lying across the opened lumen with no interdigitation of the cervical rings); (B)-grade 2 (cervices had a mixture of complete rings (as in grade 1) and incomplete cervical rings that lay partially across the opened lumen and interdigitated with one another); and (C)-grade 3 (cervices had predominantly incomplete and interdigitating cervical rings that were not aligned. White arrows illustrate the maximum depth of penetration with a rigid, metal catheter. Modified from Kershaw et al. [19]. 
cryopreservation is accompanied by a redistribution of lipids comprising the cell membrane of the spermatozoa that alters lipid-lipid and lipid-protein relations necessary for normal sperm functioning [15]. Investigations into improving these procedures by employing various cryoprotective agents are ongoing. Thus, considering the potentially lower quality of AI semen, intrauterine deposition eliminates the adverse effects on sperm transport or survivability that are imposed by the distal segment of the ewe's reproductive tract. It is possible to obtain lambing rates of $50-80 \%$ with frozenthawed semen deposited directly in the uterine horn [5]. Understandably, for ET in sheep, the successful implantation and subsequent development of the transferred embryos is critically dependent on the intrauterine placement.

It is an understatement that the sheep industry would benefit from the increases in reproductive efficiency and genetic gains offered through AI and MOET since the global demand for sheep products is rising, with the demand currently exceeding the supply [16]. According to the Canadian Sheep Federation, the demand for Canadian lamb has increased by $64 \%$ since 1997 . Additionally, sheep are ideal candidates for the production of recombinant pharmaceutical proteins in the mammary gland [17]. This method of expressing human proteins in the milk of transgenic animals offers a safe and renewable source of clinically important proteins that cannot be produced as effectively and in adequate quantities with alternate approaches. Successful production of Factor IX, Factor VIII, heterotrimeric fibrinogen, and $\alpha_{1}$ antitrypsin has been accomplished in sheep [17].

\section{ANATOMICAL STRUCTURE OF THE OVINE CERVIX AS A MAJOR FACTOR LIMITING THE WIDESPREAD USE OF TCAI/ET IN SHEEP}

The ovine cervix has a distinctive, highly complex structural arrangement that precludes easy transcervical passage and intrauterine deposition using conventional AI catheters in non-pregnant animals. It is a very long and narrow fibrous organ (Fig. 1), comprised of mainly connective tissue with an outer serosal layer and inner luminal epithelium [18, 19]. The inner lumen adopts a tortuous quality due to the presence of characteristic funnel-shaped, caudally facing rings (Fig. 2) that project into the lumen along the length of the cervix $[18,19]$. This causes a drastic narrowing of the lumen, which is the most constricted at the first two caudal rings. The ostium of each cervical ring is $\sim 2.7 \mathrm{~mm}$ in diameter and is not concentrically aligned with that of adjacent rings. As a result, advancing a pipette through the cervix is problematic due to the difficulty in locating the opening of each successive, eccentrically positioned ring, in addition to a very small luminal diameter [18]. There is a great deal of variability in cervical morphological characteristics between breeds and individual ewes, including the length $(5-10 \mathrm{~cm})$, number of rings (3-7), ring ostium diameter (1-3 $\mathrm{mm})$, and the distance between rings $(3-5 \mathrm{~cm})$ [18-20]. It has also been suggested that the number of folds present increases with age and parity [18]. Therefore, designing a customized AI catheter for sheep has been particularly challenging [21]. Furthermore, the highly constricted external aperture of the cervix, or cervical os that extends into the vagina, is immediately surrounded and, in many cases, completely obscured by vaginal folds of fibrous tissue [19]. The configurations manifested by the external os cervix and surrounding vaginal folds are also highly variable between ewes (Fig. 3).

\section{SURGICAL AI/ET TECHNIQUES IN SHEEP}

Because of the convoluted structure of the cervix, the primary AI methods used to obviate this anatomical barrier and consistently achieve uterine semen deposition in sheep involve surgical procedures [5]. Intrauterine AI in sheep is usually performed via mid-ventral laparotomy, with or without the aid of a laparoscope [22]. Laparoscopic AI involves making two incisions under local anaesthesia; one incision is for the insertion of an endocope while an inseminating pipette is introduced into the uterine lumen through the other. Although considered a fairly simple surgical procedure, laparoscopic intrauterine AI is nevertheless invasive and causes undue stress to the animal. It is time consuming, costly, labor intensive, and requires specialized equipment and qualified personnel to perform the procedure. Repeated use of this method remains a concern for animal welfare. As a result, the use of $\mathrm{AI}$ is not widespread in the sheep industry and is limited to small flocks of usually rare, expensive, heritage breeds.

Similarly, the tortuous structure of the ovine cervix impedes a transcervical route for the deposition of harvested embryos in recipient ewes during ET procedures. In order to perform ET in sheep, similar surgical procedures to those employed for AI are necessary to deposit embryos directly in

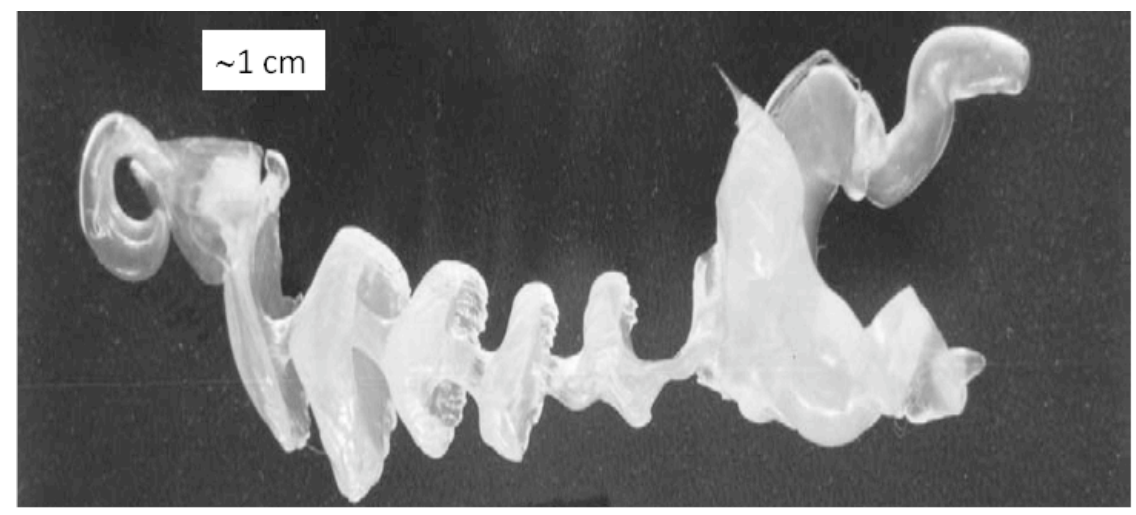

Fig. (2). A silicone mould of the inner cervical lumen of an adult ewe depicting the funnel-shaped cervical rings. Courtesy of Dr. Chris Buschback (SR Genetics, Markdale, ON, Canada). 

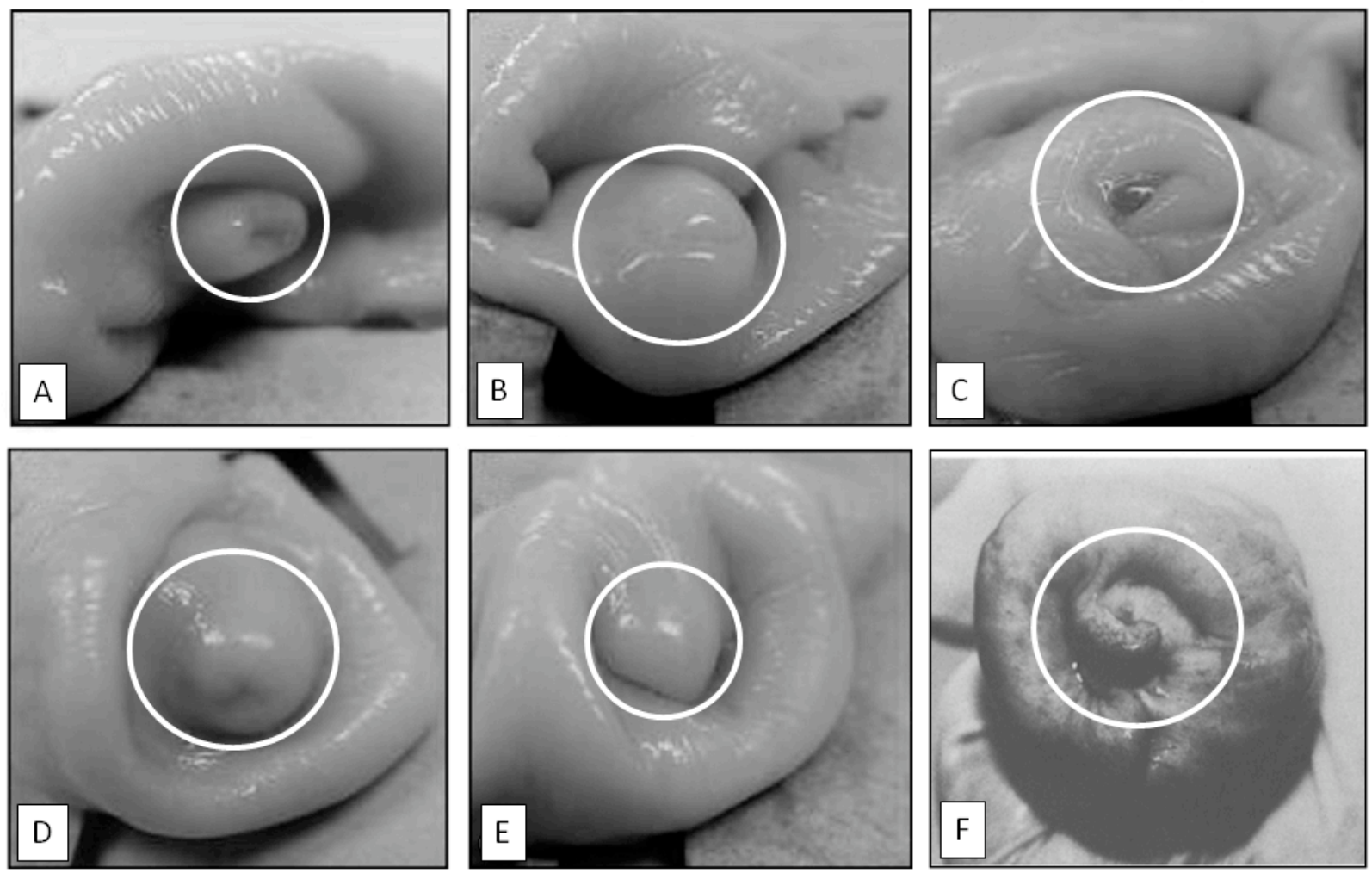

Fig. (3). The classification of the appearance of the external os cervix and surrounding vaginal folds: (A)-duckbill, (B)-slit, (C)-rose, (D)papilla, (E)-flap, and (F)-spiral. White circles indicate the location of the os cervix. Adapted from Halbert et al. [18] and Kershaw et al. [19].

the uterus [23]. As a result, ovine ET protocols possess the same pros and cons as those associated with surgical intrauterine AI. The cost to benefit ratio of surgical transfers is not favorable especially if transfers to multiple recipients are performed. Wulster-Radcliffe et al., [24] were able to achieve cervical penetration and intrauterine embryo deposition in sheep. In terms of embryonic development posttransfer, it was found that $53.5 \%$ of embryos were retained at day 12 of pregnancy with $73.3 \%$ of these embryos having matured to a stage indicative of day 12 development. Although promising, these results were never repeated and the development of the transferred ovine embryos past day 12 in utero was not assessed. A reliable transcervical method for embryo transfer would be a valuable asset to the sheep industry.

\section{THE TRANSCERVICAL APPROACHES TO AI AND ET}

The ability to gain from the benefits of AI and MOET in commercial settings is predominantly due to efficiency and ease with which these procedures can be performed. Surgical intervention is not necessary to perform intrauterine AI in large animals but rather an inseminating pipette is passed through the cervix. In cattle, the recto-vaginal approach for transcervical insemination is commonplace [8]. The deposition of semen directly into the uterine lumen, and the transcervical route used to achieve this, are the key factors owing to the commercial applicability of these procedures and the attainment of optimal conception rates; vaginal semen depo- sition is associated with considerably lower conception rates. ET can also be performed using transcervical route, and furthermore, transcervical techniques are potential alternatives for surgical methods of embryo/oocyte recovery [25].

\section{CUSTOMIZATION OF CATHETERS FOR TCAI/ET IN SHEEP}

Various modified AI/ET catheters/pipettes have been devised for the specific purpose of traversing the ovine cervix non-invasively (Fig. 4). The standard, straight-tipped cattle AI gun consists of a stainless steel barrel with a diameter of 3-4 $\mathrm{mm}$ and length of $46 \mathrm{~cm}$. It is designed to carry a plastic 0.2 -cc or 0.5 -cc straw containing semen in a fluid extender. A plunger at the proximal end of the barrel is depressed to dispel inseminate. Considering that the average diameter of the ovine cervix is $2-3 \mathrm{~mm} \mathrm{[26],} \mathrm{and} \mathrm{is}$ significantly more sinuous than the bovine cervix, the cattle AI gun is too large and not appropriate for use in sheep. Halbert et al., [26] found that a straight plastic Capristol inseminating syringe with a thin chamber syringe sheath could not be advanced past the cervical os in sheep; however, when the sheath was more flexible, the instrument could be advanced further, although it was still too large to traverse the entire cervix. Therefore, the modifications of the standard design to adapt it to the unique features of the ovine cervix involved altering the distal portion of the barrel. The use of a malleable probe with a bent end was more successful in terms of greater cervical penetration, while using a rotating motion accompanied by gentle pressure to 

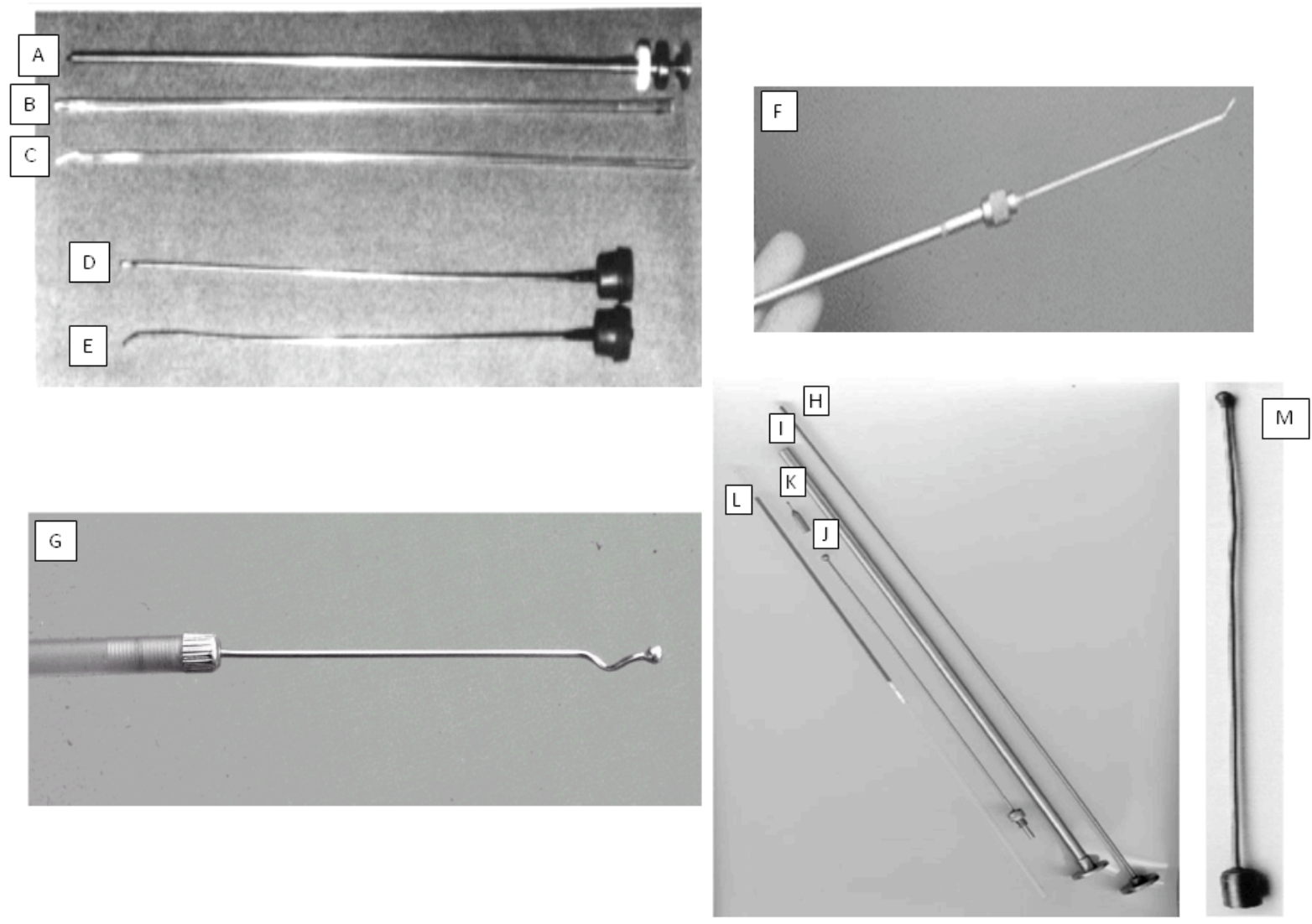

Fig. (4). Instruments used for transcervical passage in ewes. (A-E) Capristol inseminating syringe (A) with thin chamber straight sheath (B) and flexible sheath (C). A malleable probe with a straight tip (D) and bent tip (E) (modified from Halbert et al. [18]). (F)-a bent-tipped AI catheter developed by Buckrell et al. [27], and using an 18-gauge stainless steel spinal needle with a blunt tip attached to a bovine AI gun barrel shortened to $28 \mathrm{~cm}$. (G)-a tip of the Milovanov catheter, with characteristic helicoidal shape, attached to a 25-cm plastic tube [13]. (HM) Dual-purpose AI/ET instruments used by Wulster-Radcliffe et al. [32, 33]. A plunger for retro-load AI barrel (H), retro-load AI barrel (I), semi-flexible AI/ET catheter $(\mathbf{J})$ in comparison to a standard laparoscopic AI needle $(\mathbf{K}), 0.5$-cc semen straw $(\mathbf{L})$. The last frame depicts a larger view of the 17-gauge semi-flexible AI/ET catheter with bulbous tip (M).

progress past each cervical ring [26]. It was also suggested that the diameter of the insemination instrument should not exceed the diameter of the narrowest section of the cervix $[18,26]$. This prompted Buckrell et al., [27] to develop a bent-tipped AI catheter using an 18-gauge stainless steel spinal needle with a Luer-Lok screw top hub, which was modified to attach to a screw on the anterior end of a bovine AI gun barrel. The apparatus is designed for 0.5-cc semen straws and shortened to a length of $28 \mathrm{~cm}$. The pointed end of the needle is soldered until blunt to reduce cervical trauma and bent at a $45^{\circ}$ angle at $9.8 \mathrm{~mm}$ from the tip, a measure representing the average distance of greatest offset of the successive cervical rings [18]. The bent end was also drilled to create an aperture for fluid to pass through [27]. Other catheters that have been developed have a winding, helicoidal end. The Milovanov catheter consists of an 80mm stainless steel needle with a bulb at the tip attached via a screw to a $25-\mathrm{cm}$ plastic tube from which a connected syringe dispenses the inseminate [13]. Kaabi et al., [28] have shown that the bent-tipped catheter allowed significantly deeper cervical penetration than a straight-tipped catheter and Eppelston et al., [12] have shown that the spiral-tipped insemination instruments offer no particular benefit to cervical penetration depth over the bent-tipped models. The improved efficacy of bent ball-tipped probes has also been confirmed by Fukui and Roberts [29], and Campbell et al. [16]. Other catheters have been manufactured from the internal cannula of the Verres needles, 14-gauge angiocanths with blunted stylets, and Hank's dilators [30]. The use of a fiberoptic scope apparatus known as a Gourley scope was also considered for transcervical AI. Even though a preliminary trial revealed that the proportion of ewes in which transcervical passage was possible with the Gourley scope was equivalent to the laparoscopic AI technique, procedure time was twice as long with the Gourley [31]. Additionally, the scope is very costly. Wulster-Radcliffe et al., [32] developed a dual purpose $\mathrm{AI} / \mathrm{ET}$ catheter, comprised of a 17-gauge semi-flexible, $17.5-\mathrm{cm}$ stainless steel tube with a bulbous tip. The catheter's proximal end was attached to an AI gun with a retro-load feature such that loading of the straw into the gun could be completed after the tip had been advanced through the entire cervix, minimizing the amount of environmental exposure endured by the semen/embryos. The internal tube diameter is $1.07 \mathrm{~mm}$ and the external diameter is $1.47 \mathrm{~mm}[24,32,33]$, which is smaller than the average diameter of the cervical lumen in sexually mature ewes. 


\section{THE GUELPH SYSTEM FOR TCAI}

A specific technique for ovine TCAI using the catheter described by Buckrell et al., [27] was developed at the University of Guelph and denoted the "Standardized Guelph system for TCAI". This technique involves positioning the ewe in dorsal recumbency using a hoof trimming cradle, a device colloquially known as a "sheep flipper" (Fig. 5). A lubricated, plexiglass vaginoscope (tubular speculum) is inserted into the vagina and a penlight is used to observe the cervical os. Forceps are then used to grip and retract the tissue surrounding the cervical os, after which the insemination instrument is carefully maneuvered through the spiral folds of the cervix to eventually deposit semen in the body of uterus, usually near the uterine bifurcation [34].

In terms of efficiency, studies have shown that the proportion of ewes achieving complete cervical penetration with
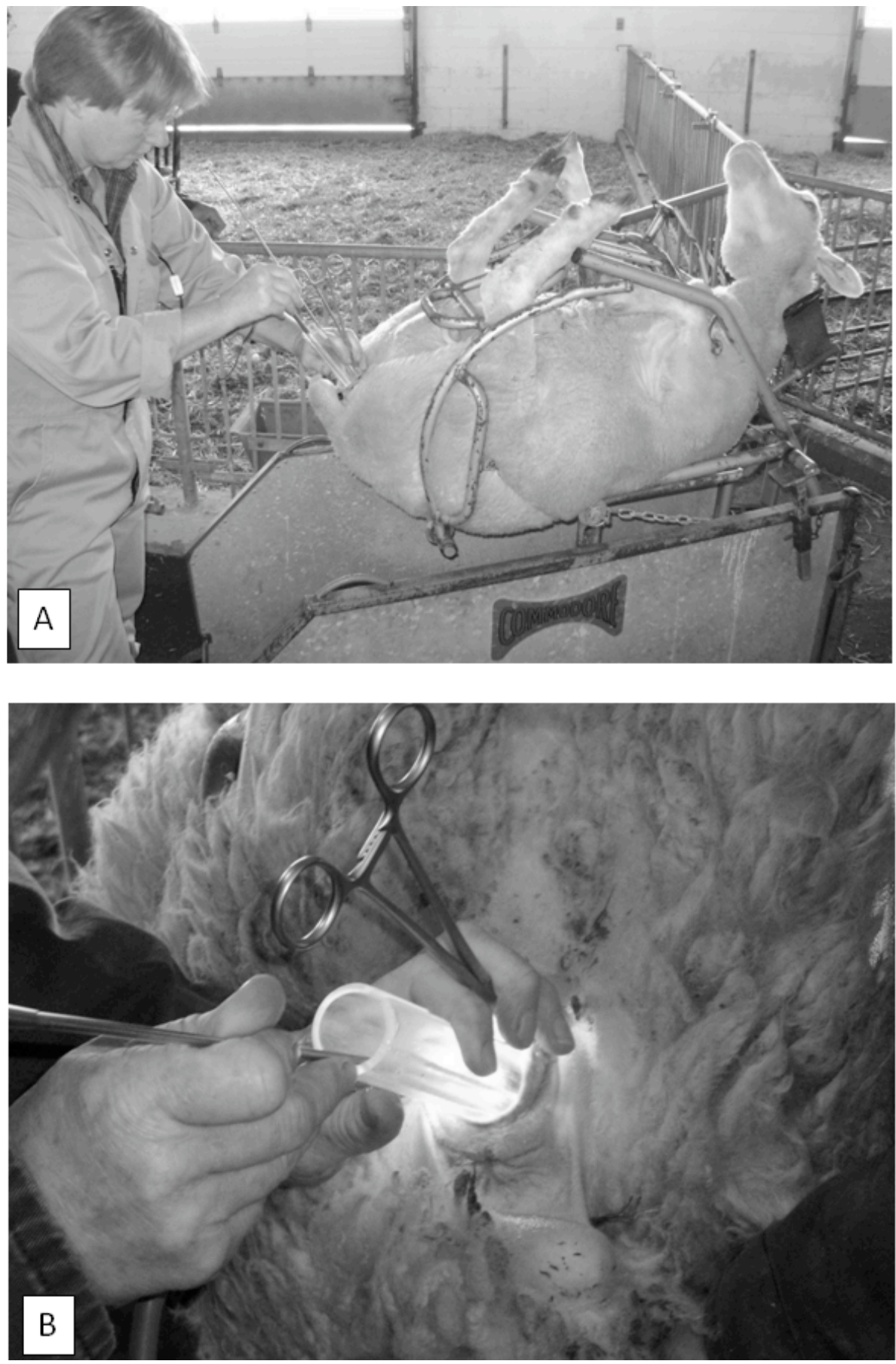

Fig. (5). The Standardized Guelph System for Transcervical Artificial Insemination (TCAI) in ewes. (A)-a ewe is restrained in a hoof trimming cradle, and then rotated in a clockwise direction $140^{\circ}$ to $150^{\circ}$ and placed in a fetal-like position and dorsal recumbency, with the hindquarters slightly elevated; (B)-a lubricated plexiglass speculum with light source is inserted into the vagina and forceps are used to retract the os cervix. Subsequently, a bent-tipped and preloaded insemination gun is manipulated through the cervix to deposit semen in the uterine lumen. 
this and similar methods ranged from $44 \%$ to $91 \%$ [13, 18 , $20,26,29,34-37]$. Reports on the total time taken to complete the procedure are $0.5 \mathrm{~min}$ to $4.8 \mathrm{~min}$. The lambing rates resulting from the Guelph system ranged from $60 \%$ to $80 \%$ using fresh semen and from $40 \%$ to $70 \%$ of successfully penetrated ewes inseminated with frozen-thawed semen. The lambing rates were significantly higher for ewes bred during the traditional fall breeding seasons than during other times of the year [27]. Evidently, the Guelph system shows promise as a non-surgical alternative to laparoscopic intrauterine deposition of semen in ewes. The technique, however, currently possesses several problems. As with similar approaches, the success of the method is highly dependent on the proficiency of the operator/inseminator [27, 35]. Even with sufficient skill, there is considerable variability between ewes in terms of the ease with which the procedure can be performed. The physiological characteristics of the ewe such as age, breed, individual variation in cervical structure, parity, season, and reproductive history may all contribute to this variability. Windsor et al., [36] and Szabados et al., [13] have shown a positive correlation between ewe parity and the depth of cervical penetration using an AI catheter and presently the method is not recommended for nulliparous ewes. Kaabi et al., [28] found a significant difference in cervical penetrability between the Assuf, Churra, Castellana and Merino breeds; upon a morphometric analysis of the cervices from these breeds, they noticed significant breedrelated differences in cervical length, width, number of folds, and the distance between folds. Halbert et al., [18] noticed that cervical penetrability was greater in ewes that had recently lambed. The Guelph system is also associated with a significant risk of cervical puncture, increasing the chance of infection and greatly decreasing fertility. One study reported a few instances of discrete pericervical abscessation, cervical lesions tracking to peritonitis, metritis and pyometra following the transcervical insemination [10]. Another study observed damage and local inflammation of the cervical epithelial lining post TCAI [16]. Raynal and Houdeau [38] purport that cervical trauma may damage sensitive zones that lead to a hormonal imbalance in the post-ovulatory period. In summary, the major problems with TCAI are the inconsistency in terms of the ability to penetrate the cervix and achieve acceptable lamb productivity. Lastly, it may be possible to modify the Guelph system for use with ET such that the pipette is made to carry a straw containing the embryos instead of semen; however, the efficacy of the method in this regard has yet to be evaluated.

\section{PHARMACOLOGICAL INDUCTION OF CERVI- CAL DILATION}

Although several modified catheters have been developed to better suit the application in ewes, the penetration rates remain inconsistent and unpredictable, and cervical trauma caused by attempts to manipulate a highly constricted cervix may have a negative impact on resulting lambing rates or future reproductive performance. A plausible solution to these obstacles would be to devise a means of softening or dilating the ovine cervix to enlarge the cervical lumen and thus ease the passage of AI/ET instruments. Cervical dilation could also increase the ease of transcervical AI/ET making it less dependent on inseminator skill and decreasing the amount of time taken to perform the procedure. Dilation of merely the first two caudal folds of the cervix, which are the most constricted and frequently misaligned, could be sufficient to facilitate transcervical instrument passage.

\section{STRUCTURAL ELEMENTS OF THE OVINE CERVIX AT VARIOUS REPRODUCTIVE STATES}

The uterine cervix undergoes tremendous structural changes in order to fulfill a diverse array of functions [39]. In its constricted state, the cervix acts as a protective barrier to ascending infections yet can simultaneously allow the passage of spermatozoa into the uterus. The maintenance of pregnancy requires the cervix to retain a fairly rigid structure in spite of increasing gravitational forces imposed by a growing conceptus and expanding uterus. The onset of parturition is accompanied by a gradual softening followed by a very rapid cervical dilation during active labor. Postpartum, the cervix must return to its rigid, constricted state to prevent the entry of infectious agents.

The molecular composition of the cervix differs from that of the uterus, which is comprised mainly of smooth muscle fibers. The cervix consists predominantly of connective tissue, and only contains a small amount of smooth muscle bundles running longitudinally and transversely [39]. The functional properties of the cervix are dependent on the biochemical interactions of the molecules comprising the extracellular matrix of the cervical connective tissue, the main component of which are collagen fibrillae packed into dense bundles and embedded in high-molecular-weight proteoglycan complexes [39]. Several endocrine factors regulate the interactions of these ultrastructural elements, mediating the extensively dynamic remodeling processes in the cervix [39].

The endocrine status of ewes presented for AI, and especially those selected for ET, is different from that of pregnant ewes at term, and thus the mechanical properties of the cervix are different as well. Ewes are seasonally polyestrous with an estrous cycle spanning approximately 17 days [40, 41]. At the time of AI, ewes are in the estrus phase, which is characterized by surges of FSH and LH from the anterior pituitary gland. This phase lasts $30-36$ hours and spontaneous ovulation, in which a phasic LH release is triggered by increasing concentrations of estrogen independent of a mating stimulus, occurs 24 to 30 hours after the onset of sexual receptivity. During this time, the uterine cervix is slightly relaxed and edematous. Conversely, at the time of ET, recipient ewes are in diestrus, during which stage the corpus luteum (CL) becomes fully functional. Luteal progesterone exerts a dominant influence on the motility and secretory function of oviducts, uterus, and vagina, and it also governs the preparation of the uterus for implantation. The cervix at this time is firm and non-edematous [42]. Kershaw et al., [19] found that mean penetration depth was on the average $4.6 \mathrm{~mm}$ greater in non-luteal compared to luteal phase ewes, thus indicating that there is a certain degree of cervical softening, yet not complete dilation, occurring during the estrus phase, most likely to facilitate potential sperm transport at this time. The exact mechanisms governing this cervical softening that occurs during the follicular phase vary from those of parturition-induced cervical 


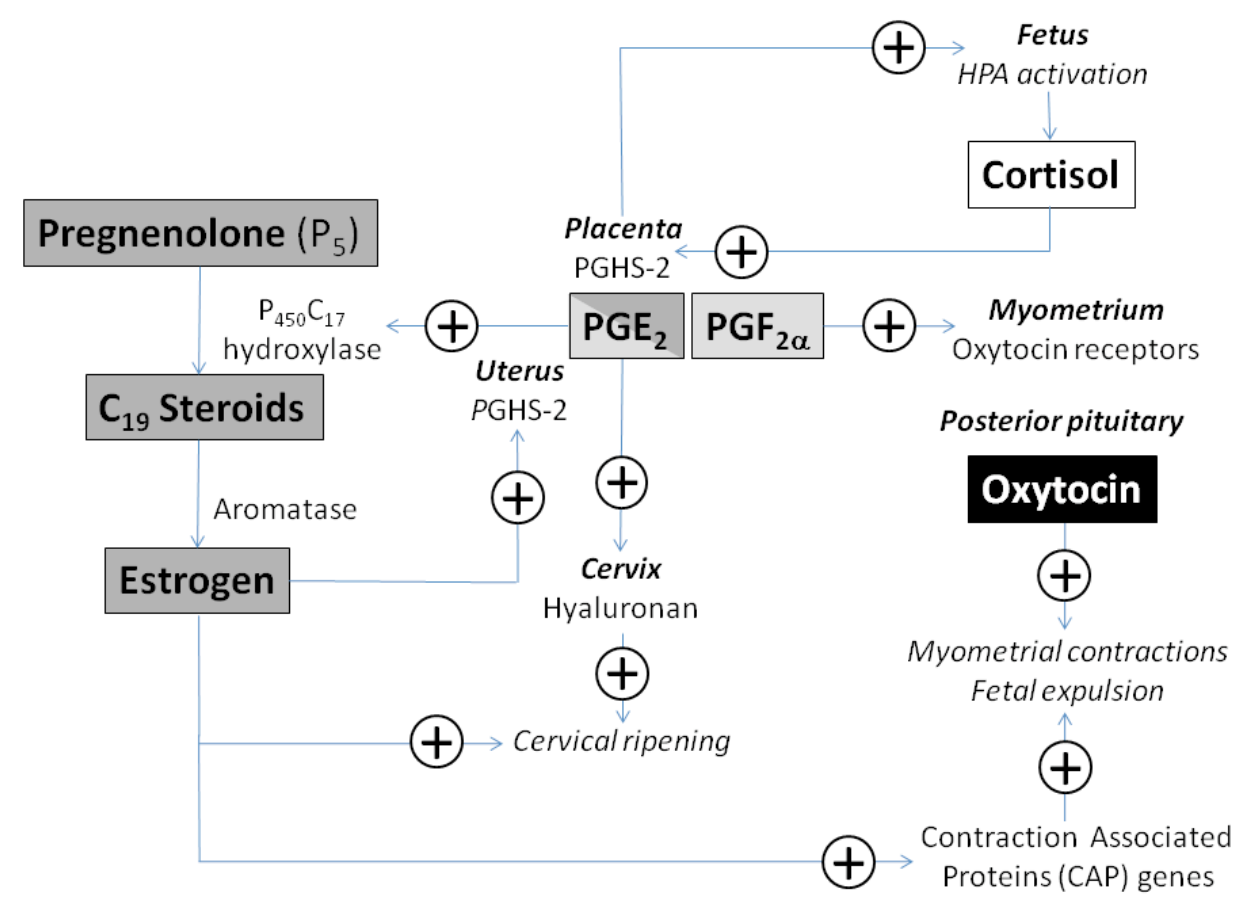

Fig. (6). A diagram of major endocrine pathways leading to the onset of parturition in sheep. (Based on Challis et al. [43] and Smith [44]).

dilation (see a section below); however, cervical softening during estrus may also be mediated by $\mathrm{PGE}_{2}$ [43]. The expression of prostaglandin $\mathrm{E}$ receptor $\left(\mathrm{EP}_{2}\right) \mathrm{mRNA}$ is greatest prior to the LH surge, although prostaglandin $\mathrm{E}$ receptors $\mathrm{EP}_{2}$ and $\mathrm{EP}_{4}$ are expressed throughout the estrous cycle in ewes [43].

\section{PUTATIVE MECHANISMS OF NATURAL CERVI- CAL DILATION IN PERIPARTURIENT EWES}

In ewes, circulating progesterone concentrations remain high throughout the course of pregnancy and placental production of estrogen is minimal due to the absence of a suitable, aromatizable substrate. At term, there is a surge in fetal adrenal cortisol production due to increased activity of the fetal hypothalamus-pituitary-adrenal (HPA) axis [44, 45]. This rise in cortisol levels results in up-regulation of prostaglandin synthase (PGHS-2) gene expression in the placenta and increased synthesis of prostaglandin $\mathrm{E}_{2}\left(\mathrm{PGE}_{2}\right)$. $\mathrm{PgE}_{2}$ feeds back to further stimulate the activity of fetal HPA and is itself responsible for up-regulation of cytochrome $\mathrm{P}_{450} \mathrm{C}_{17}$ hydroxylase in the placenta (Fig. 6). Activation of the steroidogenic enzyme leads to the conversion of progesterone to testosterone and androstenedione [43]. These molecules are then aromatized to estrogens, which results in an overall decline in progesterone levels (i.e., cessation of "progesterone block") and increased estrogen levels [44, 45]. This alteration in the ratio of progesterone to estrogen occurs a few days prior to parturition [46]. The change in the ratio of estrogen to progesterone stimulates the release of prostaglandin $\mathrm{F}_{2 \alpha}\left(\mathrm{PGF}_{2 \alpha}\right)$ from the uterus [46]. Increased placental estrogen production is required for up-regulation of PGHS-2 in maternal, but not fetal, tissues prior to labor [43]. The hormone oxytocin is released from the pituitary gland, which further increases the release of prostaglandin $E_{2}$ $\left(\mathrm{PGE}_{2}\right)$ in the pre-term uterus [47]. $\mathrm{PGE}_{2}$ acts via prostaglandin $\mathrm{E}$ receptors $\mathrm{EP}_{1}$ to $\mathrm{EP}_{4}$, and stimulation of both $\mathrm{EP}_{2}$ and $\mathrm{EP}_{4}$ receptors mediates smooth muscle relaxation and glycosaminoglycan synthesis in the cervix [43, 44]. It has been proposed that $\mathrm{PGE}_{2}$ binds to $\mathrm{EP}_{2}$ and $\mathrm{EP}_{4}$ receptors stimulating hyaluronan synthesis, which causes remodeling of the cervical extracellular matrix, culminating in cervical ripening $[43,44,48]$. Finally, the production of $\mathrm{PGF}_{2 \alpha}$ enhances the expression of oxytocin receptors in the myometrium [47]. The subsequent myometrial binding of oxytocin brings about the uterine contractions and, ultimately, the expulsion of the fetus.

\section{FEATURES OF AN IDEAL (PHARMACOLO- GICAL) CERVICAL DILATOR}

For the purposes of AI and ET, an ideal pharmacologic agent to induce cervical ripening in the non-pregnant ewe must be cost and time effective, engineered for easy delivery, and cause minimal discomfort to recipient ewes. Furthermore, such an agent should not yield adverse maternal or embryonic effects, or detrimental consequences to terminal follicular development, ovulation and oocyte quality, as well as sperm viability and transport. Therefore, it should not induce undesirable uterine effects such as atony or hyperstimulation; both of these conditions may contribute to the retrograde flow of semen deposited during AI, thus greatly decreasing the chances of fertilization. Similarly, they could interfere with the ability of a transferred embryo to successfully implant in the endometrial layer. Lastly, the agent should have the ability to induce dilation during a variety of reproductive states regardless of fluctuations in the concentrations of endogenous hormones. 


\subsection{Previous Cervical Dilation Attempts in Sheep}

Several attempts have been made to sufficiently dilate the cervix of non-pregnant ewes. The following pharmacological agents have been tested for this purpose.

\subsubsection{Relaxin}

Relaxin has been shown to play a role in the remodeling of connective tissue, inducing cervical dilation and pelvic relaxation in some mammalian species, especially pigs. Pigs have been shown to produce abundant quantities of relaxin in late pregnancy [49]. However, Salamon and Lightfoot [50] found that relaxin injected 12 hours prior to insemination in ewes had no softening effect on the cervix and did not influence the depth of semen deposition. There is little evidence to support the biosynthesis of relaxin in ruminants [51]. Roche et al., [52] located a relaxin-like gene sequence in sheep, but this gene did not give rise to RNA species in the ovaries, placenta or endometrial tissue and thus, no functional hormone could be detected.

\subsubsection{Carazolol}

Gunduz et al., [53] have proposed that as adrenergic $\beta$ receptors on the myometrium are activated during parturition, an adverse reaction of myometrial relaxation occurs, prolonging the labor. Thus, increased adrenalin levels that may result from a stress response to a TCAI procedure in ewes could also stimulate myometrial $\beta$-receptors giving rise to a weakening of the uterine tonus, which would interfere with the transport of spermatozoa within the uterus, delaying their arrival to oviducts and thus decreasing fertility. These authors suggested that the use of a $\beta$-adrenergic blocking agent such as carazolol (1-[carbazol4-yloxy]-3-isopropylamino-2-propanol), which has a structural resemblance to adrenalin and a high affinity for both $\beta_{1}$ and $\beta_{2}$ adrenergic receptors, would inhibit the negative effects that adrenalin has on uterine tone and aid in cervical dilation. However, the administration of carozolol at the dose of $0.5 \mathrm{mg} / \mathrm{ewe}$ i.m., approximately $30 \mathrm{~min}$ prior to insemination, did not facilitate cervical penetration in the Kivircik ewes during the breeding season.

\subsubsection{Pro-Inflammatory Cytokines}

Croy et al., [54] considered whether cytokines played a significant role in cervical softening in non-pregnant ewes, an idea that was prompted by a previously observed association between cytokines and the elevation of cervical collagenases in periparturient ewes. After examining whether human interleukin-8 ( $h u \mathrm{IL}-8)$ could be used to induce cervical dilation for the purpose of AI in cyclic ewes, it was concluded that it was not effective as a sole agent for sufficient cervical dilation. The ease of penetrating the cervix of $h u \mathrm{IL}-8$-treated ewes with an insemination instrument was not significantly different from that of untreated animals, with complete penetration being achieved in only few animals.

\subsubsection{Estradiol}

As described earlier, the involvement of estrogens in the processes leading to cervical dilation during parturition is well established. Owiny et al., [55] further demonstrated a direct effect of estradiol on the extensibility of ovine cervical tissue in vitro. The extensibility of strips of ovine cervical tissue obtained from Welsh Mountain ewes at day 146 of gestation was measured. Prior infusion of estradiol-17 $\beta$ for 18 hours (on day 145 of gestation) caused a 3-fold increase in cervical extensibility that is comparable to the extensibility manifested during early stages of the spontaneous labor. Owiny et al., [55] reported the presence of high extensibility in the uterine and anterior cervical zone after estradiol-17 $\beta$ treatment, suggesting that uterine contractions may be stimulated; however, whether the hyperstimulation is occurring after the treatment with estrogens remains to be determined. These authors also found that the infusion of sodium meclofenamate (MFA), a prostaglandin synthase inhibitor, alone or in combination with estradiol-17 $\beta$, effectively suppressed increases in cervical extensibility, indicating that estradiol-17 $\beta$-induced cervical softening may actually be mediated downstream by prostaglandins.

\subsubsection{Oxytocin}

There have been inconsistent results with the use of oxytocin to dilate the ovine cervix for AI. Khalifa et al., [56] demonstrated that a stainless steel rod could be passed through the cervix into the uterus in $77 \%$ of ewes treated with 200,400 or 600 USP of exogenous oxytocin injected i.v.; the same rod could not be passed transcervically into the uterus of any saline-treated animals. While the observed results (successful cervical dilation) were directly attributed to the administration of exogenous oxytocin, it was stated that the mechanism of action was not known; therefore, it is possible that the prostaglandins, especially $\mathrm{PGE}_{2}$ released in response to the injected oxytocin, was the actual agent specifically involved in cervical dilation. Conversely, King et al., [11] found that $10 \mathrm{IU}$ of i.m. oxytocin prior to TCAI in Bluefaced Leicester x Blackface ewes did not permit complete cervical penetration in ewes. Oxytocin does affect uterine contractility; exogenous oxytocin induces uterine tetany but apparently does not reduce sustained sperm transport from the uterus to the oviducts [57]. Stellflug et al. [58] showed that Western White Face ewes treated with 200 or 400 USP of i.v. oxytocin 30 or 60 min prior to TCAI had significantly decreased pregnancy and lambing rates in comparison to saline-treated controls. This effect was independent of any possible confounding effect that cervical manipulation could have had on the results. In the study by King et al., [11], treatment with oxytocin was also shown to reduce lambing rates. Therefore, although oxytocin could increase the cervical penetration rate in ewes, it is possible that fertility after oxytocin pre-treatment and TCAI may be adversely affected. In a study by Sayre and Lewis [57], the fertilization rate, which was determined 72 hours after AI, was significantly greater after laparoscopic than transcervical/cervical AI $(92.5 \%$ versus $28 \%$ ), but oxytocin treatment itself (i.e., 200 USP units of oxytocin i.v.) did not affect fertilization rate in purebred Hampshire, Dorset, and Suffolk ewes. It was concluded that exogenous oxytocin did not reduce ovum fertilization rate, but the transcervical manipulations per se seemed to reduce the fertilization rate. More studies are needed in that area.

\subsubsection{Prostaglandins}

Prostaglandins (PGs) are known to play a role in the regulation of cervical function. Increased prostaglandin levels in the uterus, cervix and fetal membranes have been 

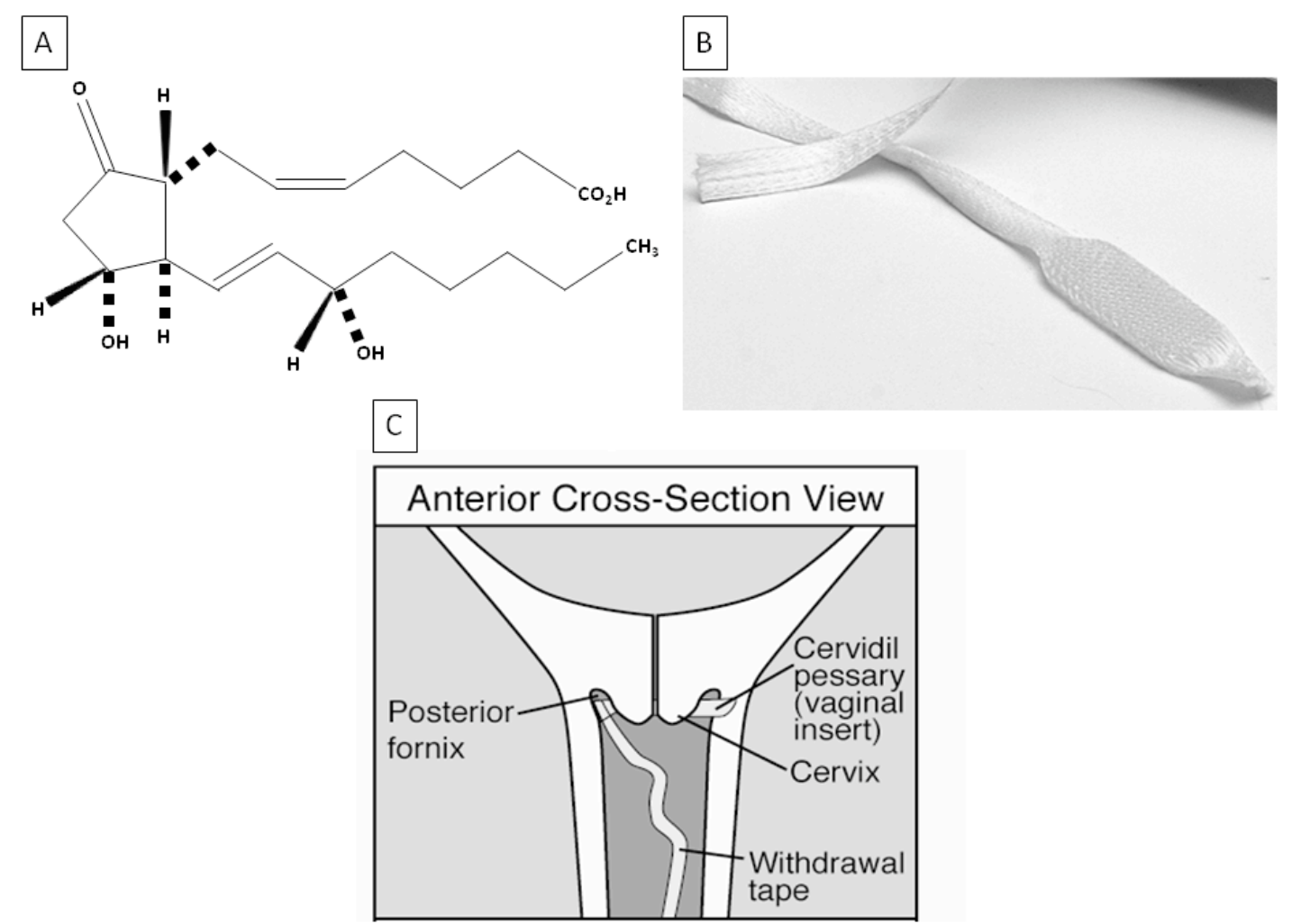

Fig. (7). (A) The structural formula of dinoprostone. (Source: www.frx.com/pi/cervidil_pi.pdf). (B) Cervidil ${ }^{\mathbb{B}}$ vaginal insert. (Source: www.frx.com/products/cervidil.aspx). (C) Appropriate positioning of a Cervidil ${ }^{\mathbb{B}}$ insert within the reproductive tract of the human female. (Source: www.secure.healthlinks.net.au/content/csl/pi.cfm? product=cspcervi10606).

observed before and during parturition, and an increase in the circulating concentration of prostaglandin metabolites is observed at the onset of labor in ewes [44].

Leethongdee et al., [59] evaluated the usefulness of misoprostol, a synthetic analogue of prostaglandin $E_{1}$ $\left(\mathrm{PGE}_{1}\right)$, as a cervical relaxant for ewes. In that study, ewes were treated intracervically with $1 \mathrm{mg}$ of misoprostol dissolved in $0.5 \mathrm{ml}$ of $30 \%$ gelatin. Previous studies had indicated that 200- $\mu \mathrm{g}$ and $400-\mu \mathrm{g}$ doses of misoprostol had been ineffective in inducing cervical relaxation 24-72 hours after administration. The higher dose seemed to confer better results with effective intrauterine penetration achieved at 54 hours post-treatment of cyclic ewes [59].

Rickords and White [60] investigated the involvement of exogenous prostaglandin $\mathrm{E}_{2}\left(\mathrm{PGE}_{2}\right)$ in cervical ripening. A single 10-mg dose of $\mathrm{PGE}_{2}$ (dinoprostone) was administered via a lipid-based vaginal suppository to anestrous ewes of various ages. Sixty-seven percent of the ewes displayed cervical dilation 3 hours post-treatment; however, complete cervical passage was possible in only one of the ewes. Also, the occurrence of rapid smooth muscle contractions of the uterus was noted. This result could be attributed to a dose effect or a rate of release of dinoprostone; it has been shown that lower concentrations of $\mathrm{PGE}_{2}$ in the early phase of labor can induce cervical ripening without inducing undesirable uterine hyperstimulation. Cabrol et al., [61] have shown that the cervix can undergo structural changes similar to those preceding normal delivery, independently of the concurrent changes in uterine contractility. Therefore, the results obtained by Rickords and White [60] have warranted further studies of the dose and/or method of delivery of dinoprostone in ewes.

Cervidil $^{\circledR}$ (Ferring Pharmaceutical Inc., York, ON, Canada) is currently used to initiate or accelerate cervical ripening in pregnant women, at or near term, in whom there is an obstetrical indication for the induction of labor. It consists of a flat, thin, semi-opaque, rectangular-shaped pessary measuring $29 \mathrm{~mm}$ by $9.5 \mathrm{~mm}$ and $0.8 \mathrm{~mm}$ in thickness, contained within a slim, polyester-knitted pouch with an attached flat, wide cord allowing for convenient retrieval of the insert from the vaginal canal (Fig. 7). The pessary is comprised of $241 \mathrm{mg}$ of a hexanetriol/macrogol 8000/isocyanate cross-linked hydrogel copolymer matrix with $10 \mathrm{mg}$ of dinoprostone dispersed within it. This specific configuration allows for the slow release of a relatively constant dose ( $\sim 0.3 \mathrm{mg}$ of dinoprostone per hour). Once the insert is placed in a moist environment, it will absorb water, swell slightly and begin releasing dinoprostone. All of the components of the insert are non-toxic and have been well tolerated in placebo-controlled trials [62-64] and clinical settings [65].

In a recent study [34], frozen-thawed semen from Dorset rams stored in 0.5-cc straws containing $150 \times 10^{6}$ sperm was successfully deposited into the uterus of all Cervidil ${ }^{\circledR}$-primed (12 hours) anestrous ewes but only four of six control ewes (Rideau Arcott, aged from 3 to 7 years), using the Standardized Guelph System for transcervical AI. In the remaining control ewes, semen was deposited into the cervix. Estrous was synchronized in all animals with CIDR (14 days) and a single injection of 500 IU PMSG given at CIDR removal. 
The average time taken to perform AI $(47 \pm 10 \mathrm{sec})$ did not differ between treated and control ewes, and there was no effect of age and parity of ewes on the time taken to perform the procedure. None of the treated or control ewes in that trial became pregnant, as based on the single transabdominal ultrasonographic examination conducted 50 days post-insemination. The treatment with Cervidil $^{\circledR}$ releasing physiological concentrations of $\mathrm{PGE}_{2}$ holds promise for being a method to dilate cervix of sheep without causing the uterine hyperstimulation, and is an easier, safer and less costly method to use than laparoscopy. However, the effects of intravaginal $\mathrm{PGE}_{2}$ application on uterine motility, sperm transport and fertilization ought to be addressed in subsequent studies. The assessment of cervical texture and rigidity may aid in determining the optimal duration of the treatment with Cervidil $^{\circledR}$ in ewes undergoing TCAI procedures. Comparisons between the breeding and non-breeding seasons will also be necessary. Lastly, the utility of the insert for inducing cervical dilation during transcervical embryo transfer or embryo retrieval after superovulatory treatments of ewes still remains to be examined.

\section{PROJECTED SIGNIFICANCE AND FUTURE DIRECTIONS OF STUDIES ON HORMONAL INDUCTION OF CERVICAL SOFTENING IN EWES}

The development of a non-surgical AI/ET technique that can be performed efficiently in ewes has consequential practical implications for the sheep industry, especially for breed improvement strategies. The use of hormonal agents may not only facilitate TCAI and TCET but could also aid in improving transcervical methods of embryo or oocyte recovery in order to replace the standard surgical technique of midventral laparotomy currently used. There are several accounts of successful embryo recovery from cattle [25] and goats $[30,66]$, and a few experimental attempts have been documented in sheep. Coonrod et al., [67] were able to advance a Foley catheter, ball-tipped needle and Verres needle through a retracted sheep cervix and inject 5-10 $\mathrm{ml}$ of phosphate buffered saline (PBS) supplemented with 5\% fetal calf serum into the uterus. Using this method, complete cervical penetration was achieved in $54 \%$ of the ewes. From the 26 ewes that were flushed, 62 blastocysts, morulae and unfertilized ova were obtained. Mylne et al., [68] found that successful cervical catheterization using a 10 FG Foley catheter could be accomplished in $65 \%$ of multiparous ewes with an embryo recovery rate of $60 \%$. Flohr et al., [69] developed a method of transcervical oocyte recovery in ewes. An 18 French Foley catheter was passed transcervically in order to inject $20-40 \mathrm{ml}$ of PBS that was aspirated using a vacuum pump after each administration. Cervical catheter penetration was possible in all 12 multiparous ewes used and the recovery rate of oocytes was $50 \%$.

Hormonal agents such as Cervidil ${ }^{\circledR}$ may also be used for the treatment of ringwomb in ewes. This is a condition seen in parturient ewes in which the normal progression of labor is arrested due to failure of the cervix to dilate, inevitably followed by dystocia $[41,70]$. The use of $\mathrm{Cervidil}^{\circledR}$ in ewes presenting ringwomb may dilate the cervix sufficiently to aid the progression of natural labor; this potential application very closely resembles the current use Cervidil ${ }^{\mathbb{P}}$ in human clinical practice.
The hormonal induction of cervical dilation may have additional applications that extend beyond the sheep industry, such as facilitating assisted-breeding programs in zoos or similar programs designed for conservation of endangered or rare species. For example, Cervidil ${ }^{\mathbb{B}}$ pre-treatment may facilitate non-invasive TCAI/ET in exotic species within a similar size, weight range and cervical anatomy as sheep, especially for those in which surgical interventions would be unsuitable or undesirable. TCAI has been attempted in various endangered even-toed ungulates such as the Suni antelope [71], Gerenuk antelope [71], Indian blackbuck antelope [72], antelopes of the family Hippotraginae [71], and various cervids such as elk [71], red deer [71, 73], and Sika deer [74]. The uterine cervix in these species is too small to employ the standard retrovaginal TCAI method [30, 71]. Morrow et al., [70] noted some difficulty in traversing the cervix of these species using a semi-flexible tipped catheter and care was taken by the inseminator not to cause damage to the cervical lining. Catheter diameters used for these species ranged from 3Fr to 14-gauge, which are similar to several catheters used in sheep. The use of ARTs is also beneficial for the commercial deer industry, which is rapidly growing in popularity. The Guelph system for AI was attempted in three species of commercially farmed deer; fallow, red and white-tailed deer [74].

The sheep is often used as the economical animal model of choice for studies involving gynaecological procedures, as the vaginal canal of the ewe is similar to that of the human female in terms of size and biophysical properties of its structural elements [75]. The transcervical intrauterine route is commonly used in both diagnostic and operative gynaecological procedures in women due to its minimally invasive nature [76]. Diagnostic procedures such as hysteroscopy, falloscopy and hysterosalpingography all can involve transcervical procedures to either advance an endoscope/microendoscope into the uterus/fallopian tubes (hysteroscopy/ falloscopy) or for the intrauterine injection of a radio-opaque contrast medium using a catheter (hysterosalpingographical fluoroscopy). Another technique that has both diagnostic and therapeutic applications is transcervical endometrial resection in which a resectoscope is passed transcervically into the uterus. Endometrial biopsies can be performed using curettage, which involves passing a transcervical device known as a curette into the uterus and scraping cell samples from the endometrial lining. Transcervical balloon tuboplasty and tubal recanalization are minimally invasive alternatives to tubal microsurgery that are used to remove occlusions in the fallopian tubes or manage tubal pregnancies [77]. Conversely, this technology can provide a minimally invasive alternative to tubal ligation for women seeking permanent sterilization. Cervical dilation prior to performing any of these procedures greatly reduces the incidence of cervical laceration during the execution of these techniques. The potential application of Cervidil ${ }^{\circledR}$ to induce dilation for this specific purpose has not been assessed as Cervidil ${ }^{\mathbb{Q}}$ is presently only indicated for labor induction in women. Currently, various mechanical methods of cervical dilation are employed in preparation for transcervical surgical procedures. The use of Hank's dilators involves passing a series of stainless steel rods with progressively larger diameters successively through the cervix. Each rod is maintained endocervically for a few minutes before being 
replaced with a larger one. This method poses a significant risk of cervical trauma in addition to causing discomfort. Alternatively, Laminaria tents induce a mechanical cervical dilation through a hydrophilic action. This process involves a hydrophilic organic substance, the most common of which being a seaweed of the species Laminaria digitata or Laminaria japonicum (or a synthetic counterpart of these materials) being placed within the cervix, after which, absorbing fluids and expanding over the course of several hours, thus dilating the cervix in the interim. In addition to the requirement of trained personnel to insert the tent, other disadvantages surrounding Laminaria tent usage include the potential risk of intrauterine tent displacement, cervical perforation and the fact that several tents may have to be inserted repeatedly to achieve the desired level of dilation, increasing the degree of associated discomfort [78]. Consequently, the incorporation of Cervidil ${ }^{\circledR}$ may provide a safe and effective method of cervical dilation for reproductive tract surgeries.

A fairly new experimental surgical technique in human medicine that is gaining increasing attention is natural orifice transluminal endoscopic surgery (NOTES; [76]). NOTES provides a means of performing "scarless" abdominal surgery guided by an endoscope passed through a natural bodily orifice and then through small internal incisions in various organs. The transvaginal route has been deemed the most safe and feasible for clinical applications [79]. A successful transvaginal donor kidney extraction [80] and transvaginal cholecystectomy [79] were performed on humans based on previous work with animal models. Future experiments involving sheep as an animal model for developing various NOTES techniques, transvaginal and/or transuterine, may benefit from the application of Cervidil ${ }^{\circledR}$ such that transcervical route may be used to allow for the repeated passage of specialized tools permitting an array of surgical interventions.

\section{CONCLUDING REMARKS}

Combining the genetic selection methods and assisted reproductive technologies (ARTs) is the most effective approach to increasing livestock productivity. By comparison to large ruminants, swine and poultry, the sheep industry has progressed rather slowly in terms of application of ARTs. The narrow lumen and complex anatomical structure of the uterine cervix are major limiting factors precluding the widespread application of non-surgical artificial insemination (AI) and embryo transfer (ET) in ewes. This inherent obstacle causes the reproductive technologies in sheep to be developed that are different from those in large mammalian species, are more difficult to perform and less cost effective. In recent years, the attempts to improve transcervical AI (TCAI) and ET (TCET) in ewes have focused primarily on using different modalities of insemination catheters and pharmacological cervical dilators to facilitate intrauterine deposition of semen or embryos. Several types of catheters, varying in the shape of the tip and degree of flexibility, have permitted a full transcervical passage in the adult ewe, but the success of the procedure still depends heavily on the skills of an operator. The selection of an optimal pharmacological agent to induce cervical dilation prior to AI or ET has been based on our knowledge of the physiological pro- cesses occurring during parturition. However, both intravaginal and systemic administration of various hormones stimulating cervical ripening in periparturient sheep and other mammalian species are yielding variable results due mainly to our inability to precisely control the dosage and/or rate of drug delivery. Sufficient cervical dilation achieved with supraphysiological doses of different agents is usually accompanied by either uterine atony or increased contractility, which may interfere with normal sperm transport in the reproductive tract of the ewe and implantation. Very promising results, in terms of cervical softening and penetrability, have recently been obtained with intravaginal, controlledrelease inserts containing prostaglandin $\mathrm{E}_{2}$ (dinoprostone; Cervidil $^{\circledR}$, Ferring Pharmaceuticals Inc.). Further evaluation of their effects on cervical texture, uterine contractility and sperm/embryo viability in cyclic and anestrous ewes is necessary. In addition, the studies on the effects of Cervidil ${ }^{\circledR}$ in an ovine experimental model may pave the way to improvements in minimally invasive obstetrical and abdominal surgery.

\section{ACKNOWLEDGEMENTS}

We would like to thank Dr. Chris Buschback (SR Genetics, Markdale, ON, Canada) for help with our research projects and preparation of this review article. The authors' research was funded by the Natural Sciences and Engineering Research Council (NSERC) of Canada, and the Ontario Sheep Marketing Agency (OSMA).

\section{CONFLICT OF INTEREST}

The authors' research described in this review was also funded, in part, by the Ferring Pharmaceuticals Inc.

\section{REFERENCES}

[1] Campbell J, Kenealy M, Campbell K. Animal sciences: the biology, care, and production of domestic animals. New York: McGraw-Hill 2003.

[2] Dekkers J. Structure of breeding programs to capitalize on reproductive technology for genetic improvement. J Dairy Sci 1992; 75: 2880-91.

[3] Fernando R, Grossman M. Marker-assisted selection using best linear unbiased prediction. Genet Sel Evol 1989; 21: 467-77.

[4] Parnell P. Best linear unbiased prediction (BLUP) and the design of breeding programs. P Aus S Ani 2004; 15: 513-6.

[5] Youngquist R, Threlfall W. Current therapy in large animal Theriogenology. $2^{\text {nd }}$ ed. St. Louis: Elsevier Inc. 2007.

[6] Betteridge K. A history of farm animal embryo transfer an some associated techniques. Anim Reprod Sci 2003; 79: 203-44.

[7] Van Doormaal B, Kistemaker G. Dairy genetic improvement through artificial insemination, performance recording and genetic evaluation. Can J Anim Sci 2003; 83: 385-92.

[8] Foote R. The history of artificial insemination: selected notes and notables. J Anim Sci 2002; 80: 1-10.

[9] Dziuk P. Embryo transfer: an experimental tool with practical applications. BioScience 1975; 25: 102-6.

[10] McKelvery B. AI and embryo transfer for genetic improvement in sheep: the current scene. In Pract 1999: 190-5.

[11] King M, McKelvery W, Dindwall W, et al. Lambing rates and litter sizes following intrauterine or cervical insemination of frozen/thawed semen with or without oxytocin administration. Theriogenology 2004; 62: 1236-44.

[12] Eppleston J, Salamon S, Moore N, et al. The depth of cervical insemination and site of intrauterine insemination and their relationship to the fertility of frozen-thawed ram semen. Anim Reprod Sci 1994; 36: 211-25. 
[13] Szabados T, Gergatz E, Vitinger E, et al. Lambing rate as a function of artificial insemination depth in ewe lambs primiparous and multiparous ewes. Acta Agraria Kaposvariensis 2005; 9: 41-9.

[14] Hawk H, Cooper B, Pusel V. Increased sperm death in the cervix and uterus of estrous ewes after regulation of estrus with prostaglandin or progestogen. J Anim Sci 1981; 52: 601-10.

[15] Bailey J, Morrier A, Cormier N. Semen cryopreservation: Successes and persistent problems in farm species. Can J Anim Sci 2003; 83: 393-401.

[16] Campbell J, Harvey $\mathrm{T}$, McDonald $\mathrm{M}$, et al. Transcervical insemination in sheep: an anatomical and histological evaluation. Theriogenology 1996; 45: 1535-44.

[17] Rudolph NS. Biopharmaceutical production in transgenic livestock. Trends Biotechnol 1999; 17(9): 367-4.

[18] Halbert G, Dobson H, Walton J, et al. A technique for transcervical intrauterine insemination of ewes. Theriogenology 1990; 33: 9931010 .

[19] Kershaw C, Khalid M, McGowan M, et al. The anatomy of the sheep cervix and its influence on the transcervical passage of an inseminating pipette into the uterine lumen. Theriogenology 64: 1225-35.

[20] Naqvi S, Joshi A, Bag S, et al. Cervical penetration and transcervical AI of tropical sheep (Malpura) at natural estrus using frozen-thawed ram semen. Small Ruminant Res 1998; 29: 329-33.

[21] Anel L, Alvarez M, Martinez-Pastor F, et al. Improvement of strategies in ovine artificial insemination. Reprod Dom Anim 2006; 41: 30-42.

[22] Killen I, Caffery G. Uterine insemination with the aid of a laparoscope. Aust Vet J 1982; 59: 95.

[23] Schiewe M, Bush M, Stuart L, et al. Laparoscopic embryo transfer in domestic sheep: a preliminary study. Theriogenology 1984; 22 : 675-82.

[24] Wulster-Radcliffe M, Costine B, Lewis G. Estradiol-17ß-oxytocininduced cervical dilation in sheep: application to transcervical embryo transfer. J Anim Sci 1999; 77: 2587-93.

[25] Ozil J, Heyman Y, Renard J. An instrument for transcervical recovery of embryos from heifers. Theriogenology 1979; 11: 17383.

[26] Halbert G, Dobson H, Walton J, et al. The structure of the cervical canal of the ewe. Theriogenology 1990; 33: 977-92.

[27] Buckrell B, Buschbeck C, Gartley C, et al. Further development of a transcervical technique for artificial insemination in sheep using previously frozen semen. Theriogenology 1994; 42: 601-11.

[28] Kaabi M, Alvarez M, Anel E, et al. Influence of breed and age on morphometry and depth of inseminating catheter penetration in the ewe cervix: a post-mortem study. Theriogenology 2006; 66: 187683.

[29] Fukui Y, Roberts E. Future studies on the non-surgical intrauterine technique for artificial insemination in the ewe. Theriogenology 1978; 10: 381-93.

[30] Kraemer D. Embryo collection and transfer in small ruminants. Theriogenology 1989; 31: 141-8.

[31] Crooks A, McKusick B, Thomas D, et al. Comparison of two artificial insemination methods in Rambouillet ewes. Proceedings of the 1999 NCR-190 Technical Committee pp. 21-23: 1999.

[32] Wulster-Radcliffe M., Lewis G. Development of a new transcervical artificial insemination method for sheep: effects of a new transcervical artificial insemination catheter and traversing the cervix on semen quality and fertility. Theriogenology 2002; 58: 1361-71.

[33] Wulster-Radcliffe M, Wang S, Lewis G. Transcervical artificial insemination in sheep: effects of a new transcervical artificial insemination instrument and traversing the cervix on pregnancy and lambing rates. Theriogenology 2004; 62: 990-1002.

[34] Candappa I, Bainbridge H, Price N, et al. A preliminary study on the suitability of Cervidil to induce cervical dilation for artificial insemination in ewes. Res Vet Sci 2009; 87: 204-10.

[35] Windsor D, Szell A, Buschbeck C, et al. Transcervical artificial insemination of Australian Merino ewes with frozen-thawed semen. Theriogenology 1994; 42: 147-57.

[36] Windsor D. Factors influencing the success of transcervical insemination in Merino ewes. Theriogenology 1995; 43: 1009-18.

[37] Husein M, Bailey M, Ababneh M, et al. Effect of eCG on the pregnancy rate of ewes transcervically inseminated with frozenthawed semen outside the breeding season. Theriogenology 1998; 49: 997-1005.
[38] Raynal P, Houdeau E. Comparison of the uterine reflex activity during artificial insemination and mating in the ewe. J Gynecol Obst Bio R 2004; 33: 725-33.

[39] Word R, Li X, Hnat M, et al. Dynamics of cervical remodelling during pregnancy and parturition: mechanisms and current concepts. Semin Reprod Med 2007; 25: 69-79.

[40] Bartlewski P, Baby T, Giffin J. Reproductive cycles in sheep. Anim Reprod Sci 2011; 124: 259-268.

[41] Goodman R. Neuroendocrine control of the ovine estrous cycle. In: Knobil E, Neill J, Eds. The physiology of reproduction. $2^{\text {nd }}$ ed. New York: Raven Press 1994; pp. 660-693.

[42] Arthur G, Noakes D, Pearson H. Veterinary reproduction and obstetrics. London: Bailliere Tindall 1989.

[43] Kershaw-Young C, Khalid M., McGowan M, et al. The mRNA expression of prostaglandin $\mathrm{E}$ receptors $\mathrm{EP}_{2}$ and $\mathrm{EP}_{4}$ and the changes in glycosaminoglycans in the sheep cervix during the estrous cycle. Theriogenology 2009 72:151-61.

[44] Challis J, Matthews S, Gibb W, et al. Endocrine and paracrine regulation of birth at termand preterm. Endocr Rev 2000; 21: 51450 .

[45] Smith, R. The endocrinology of parturition: basic science and clinical applications volume 27. Basel, Switzerland: Karger pp. 147-164; 2001

[46] Liggins C. Initiation of parturition. Brit Med Bull 1979; 35: 14550 .

[47] Weems C, Weems Y, Randel R. Prostaglandins and reproduction in female farm animals. Vet J 2006; 17: 206-28.

[48] Winkler M, Kemp B, Hauptmann S, et al. Parturition steroids, prostaglandin $\mathrm{E}_{2}$ and expression of adhesion molecules by endothelial cells. Obstet Gynecol 1997; 89: 393-402.

[49] Bagnell C, Zhang Q, Downey B, et al. Sources and biological actions of relaxin in pigs. J Reprod Fertil 1993; 48: 127-38.

[50] Salamon S, Lightfoot R. Fertility of ram spermatozoa frozen by the pellet method III. The effects of insemination technique, oxytocin and relaxin on lambing. J Reprod Fertil 1967; 22: 409-23.

[51] Renegar R, Larkin L. Relaxin concentrations in endometrial, placental and ovarian tissues and in sera from ewes during middle and late pregnancy. Biol Reprod 1985; 32: 840-47.

[52] Roche P, Crawford R, Tregar G. A single copy relaxin-like gene sequence in present in sheep. Mol Cell Endocrinol 1993; 91:21-8.

[53] Gunduz M, Turna $\mathrm{O}$, Cirit $\mathrm{U}$, et al. Lambing rates and litter size following carazolol administration prior to insemination in Kivircik ewes. Anim Reprod Sci 2010; 118: 32-6.

[54] Croy B, Prudencio J, Minhas K, et al. A preliminary study on the usefulness of huIL-8 in cervical relaxation of the ewe for artificial insemination and embryo transfer. Theriogenology 1999; 52: 27187.

[55] Owiny J, Fitzpatrick R, Spiller D. Changes in the extensibility of the ovine cervix uteri following infusion of estradiol-17 $\beta$ at term. Small Ruminant Res 1992; 7: 75-83.

[56] Khalifa R, Sayre B, Lewis G. Exogenous oxytocin dilates the cervix in ewes. J Anim Sci 1992; 70: 38-42.

[57] Sayre B, Lewis G. Fertility and ovum fertilization rate after laparoscopic or transcervical intrauterine artificial insemination of oxytocin-treated ewes. Theriogenology 1997; 48: 267-75.

[58] Stellflug J, Wulster-Radcliffe M, Hensley E, et al. Oxytocininduced cervical dilation and cervical manipulation in sheep: effects on laparoscopic artificial insemination. J Anim Sci 2001; 79: 568-73.

[59] Leethongdee S, Khalid M, Bhatti A, et al. The effects of prostaglandin analogue misoprostol and follicle-stimulating hormone on cervical penetration in ewes during the peri-ovulatory period. Theriogenology 2007; 67: 767-77.

[60] Rickords L, White K. Dinoprostone induced cervical dilation in the ewe. Theriogenology 1988, 29: 296.

[61] Cabrol D, Dubois P, Selbon E, et al. Prostaglandin $\mathrm{E}_{2}$ induced changes in the distribution of glycosaminoglycans in the isolated rat uterine cervix. Europ J Obstet Gyn R B 1987; 26: 359-65.

[62] Rayburn W, Wagner R, Barass V, et al. An intravaginal controlledrelease prostaglandin- $E_{2}$ pessary for cervical ripening and initiation of labor at term. Obstet Gynecol 1992; 79: 374.

[63] Witter F, Merce B. Improved intravaginal controlled-release prostaglandin $\mathrm{E}_{2}$ insert for cervical ripening at term. J Matern-Fetal Neo M 1996; 5: 64-9. 
[64] Witter F, Rocco L, Johnson T. A randomized trial of prostaglandin $E_{2}$ in a controlled-release vaginal pessary for cervical ripening at term. Am J Obstet Gynecol 1992; 166: 830-4.

[65] Rath W. A clinical evaluation of controlled-release dinoprostone for cervical ripening-a review of current evidence in hospital and outpatient settings. J Perinat Med 2005; 33: 491-9.

[66] Sohnrey S. Transcervical embryo collection in Boer goats. Small Ruminant Res 2000; 36: 195-200.

[67] Coonrod S, Coren B, McBride B, et al. Successful non-surgical collection of ovine embryos. Theriogenology 1986; 25: 149-55.

[68] Mylne M, McLelvey W, Fernie K, et al. A report on the use of a transcervical technique for embryo recovery in sheep. Vet Rec 1992; 130: 450-1.

[69] Flohr S, Wulster-Radcliffe M, Lewis G. Development of a transcervical oocyte recovery procedure for sheep. J Anim Sci 1999; 77: 2583-7.

[70] Hindson J. Ringwomb in the ewe. Vet Rec 1961; 73: 85.

[71] Morrow C, Penfold L, Wolfe, B. Artificial insemination in deer and non-domestic bovids. Theriogenology 2009; 71: 149-65.

[72] Sontakke S, Patil M, Umapathy G, et al. Ejaculate characteristics, short-term semen storage and successful artificial insemination following synchronization of oestrus in the Indian blackbuck antelope (Aantilope cervicapra). Reprod Fertil Develop 2009; 21: 749-56.
[73] Garde J, Martinez-Pastor F, Gomendio M, et al. The application of reproductive technologies to natural populations of red deer. Reprod Dom Anim 2006; 41: 93-102.

[74] Willard S, Neuendorff D, Lewis A, et al. A comparison of transvaginal artificial insemination procedures for use in commercially farmed deer. Small Ruminant Res 2002; 44: 135-40.

[75] Mitchell B, TaggartM. Are animal models relevant to key aspects of human parturition? Am J Phys Reg I 2009; 297: 525-45.

[76] Giday S, Buscaglia J, Althaus J, et al. Successful diagnostic and therapeutic intrauterine fetal interventions by natural orifice transluminal endoscopic surgery (with videos). Gastrointest Endosc 2009; 70: 377-81.

[77] Schill T, Bauer O, Felberbaum R, et al. Transcervical falloscopic dilatation of proximal tubal occlusion. Is there and indication? Hum Reprod 1999; 14: 137-44.

[78] Ho P, Tsang S, Ma H. Reducing the induction to abortion interval in termination of second trimester pregnancies: a comparison of mifepristone with laminaria tent. Br J Obstet Gynaecol 1995; 102: 648-51.

[79] Bessler M, Stevens P, Milone L, et al. Transvaginal laparoscopically assisted endoscopic cholecystectomy: a hybrid approach to natural orifice surgery. Gastrointest Endosc 2007; 66: 1243-5.

[80] Gill I, Cherullo E, Meraney A, et al. Vaginal extraction of the intact specimen following laparoscopic radical nephrectomy. J Urol 2002; 167: 238-41.

(C) Candappa and Bartlewski; Licensee Bentham Open.

This is an open access article licensed under the terms of the Creative Commons Attribution Non-Commercial License (http: //creativecommons.org/licenses/bync/3.0/), which permits unrestricted, non-commercial use, distribution and reproduction in any medium, provided the work is properly cited. 